\title{
Formación política de la Organización Regional Indígena del Valle del Cauca para la participación en Ios escenarios del postconflicto en Colombia
}

\author{
Carlos Andrés Tobar Tovar - Pontificia Universidad Javeriana Cali ${ }^{1}$
}

DOI: https://doi.org/10.5565/rev/periferia.596

\begin{abstract}
Resumen
En este artículo describimos las posturas que tienen los líderes de la Organización Regional Indígena del Valle del Cauca (de aquí en adelante ORIVAC) sobre su participación en los procesos de deliberación sobre la paz. Nos hemos centrado en la descripción de la experiencia etnográfica resultante de un proceso de reflexión sobre las expectativas que genera el fin del conflicto con la guerrilla de las Fuerzas Armadas Revolucionarias de Colombia - Ejército del Pueblo (de aquí en adelante FARC-EP) en los territorios habitados por indígenas. En ese orden de ideas, el artículo evidencia las condiciones que hicieron posible el encuentro con la ORIVAC abordando los desafíos asociados con las demandas económicas y culturales que se encuentran en la base de las solicitudes de reconocimiento político.
\end{abstract}

Palabras clave: grupos indígenas, paz, postconflicto, Colombia.

Abstract. Political formation of the Regional Indigenous Organization of Valle del Cauca for participation in post agreement scenarios in Colombia

\footnotetext{
${ }^{1}$ Doctor en Antropología Social y Cultural de la Universidad Autónoma de Barcelona. Profesor asistente del Departamento de Comunicación y Lenguaje de la Pontificia Universidad Javeriana Cali. Correo: catobar@javerianacali.edu.co

Agradecimientos a las profesoras María Valdés Gásquez y Anna María Piella Vila de la Universitat Autònoma de Barcelona por la discusión alusiva a estos asuntos, en el marco de la dirección de la tesis doctoral titulada Alcance ético-político de la atención diferencial de los pueblos indígenas en Colombia: el caso del pueblo embera chamí del resguardo Wasiruma, municipio de Vijes, Valle del Cauca.
}

Este artículo se derivó de una comunicación titulada Political formation of the Regional Indigenous Organization of Valle del Cauca (ORIVAC) for participation in post agreement scenarios in Colombia. La versión inicial fue presentada el 22 de julio de 2016 en la ciudad de Milán (Italia) en el panel The praxis of collaborative ethnography: knowledge production with social movements. El panel formó parte de la 14th Biennial Conference of the European Association of Social Anthropologists (EASA 2016).

Asimismo, es un producto vinculado al proyecto de investigación Configuración de una gramática moral para el reconocimiento en el marco de la tensión ético-política entre el Estado y los indígenas embera chami que habitan el resguardo Wasiruma en Vijes, Valle del Cauca. El proyecto fue financiado por la Pontificia Universidad Javeriana Cali en el periodo enero-diciembre de 2015 (Código del proyecto 20100433). 
Carlos Andrés Tobar Tovar, Formación política de la Organización Regional Indígena del Valle del Cauca para la participación en los escenarios del postconflicto en Colombia, perifèria 22(2), diciembre 2017

\section{revistes.uab.cat/periferia}

This article describes the positions held by the leaders of the Organización Regional Indígena del Valle del Cauca (ORIVAC) about their participation in the processes of deliberation on peace. We have focused on the description of the ethnographic experience resulting from a process of reflection on the expectations generated by the end of the conflict with the guerrilla of the Fuerzas Armadas Revolucionarias de Colombia- Ejército del Pueblo (FARC-EP) in the territories inhabited by indigenous peoples. In this context, the article highlights the conditions that made possible the encounter with the ORIVAC addressing the challenges associated with the economic and cultural demands that lie at the basis of demands for political recognition.

Keywords: Indigenous Groups, Peace, Postconflict, Colombia.

\section{Introducción}

Este artículo se fundamenta en la reflexión propuesta por los miembros de la Organización Regional Indígena del Valle del Cauca (ORIVAC) respecto a un proceso de formación política en el cual participaron entre junio de 2015 y abril de 2016. Las posturas propuestas constituyen el resultado de los procedimientos metodológicos de corte etnográfico, que tenían como finalidad la consolidación de condiciones para la participación de las comunidades indígenas del departamento en el escenario sociopolítico del postconflicto.

Nos hemos propuesto, como objetivo general, describir las posibilidades y limitaciones derivadas de las posiciones que tienen los líderes indígenas sobre la participación en el nuevo marco de participación democrática que se abre para la construcción de paz en Colombia: aquello que la opinión pública y el Estado colombiano han denominado postconflicto. Tales expectativas constituyen un punto de partida para la comprensión de las perspectivas complementarias que ayudan a pensar el lugar de los grupos étnicamente diferenciados en el ámbito del conflicto armado.

En Colombia se ha avanzado en un acuerdo para el cese del conflicto con la guerrilla de las FARC-EP y eso tiene repercusiones en los grupos que habitan las zonas donde históricamente se ha dimensionado el conflicto social colombiano. Los diálogos de paz que se realizaron en La Habana representan una oportunidad histórica para deslegitimizar la violencia armada y avanzar en la búsqueda de una sociedad incluyente, pluralista y democrática (González González, 2016). Dicho de 
Carlos Andrés Tobar Tovar, Formación política de la Organización Regional Indígena del Valle del Cauca para la participación en los escenarios del postconflicto en Colombia, perifèria 22(2), diciembre 2017

\section{revistes.uab.cat/periferia}

otra forma: se trata de la cimentación de una sociedad capaz de tramitar sus conflictos por la vía del diálogo democrático que se establece en el replanteamiento de los escenarios institucionales del Estado. Dentro de esta experiencia de organización política, la ORIVAC intenta circunscribir sus perspectivas de acción social y por ello la urgencia de pensar los lenguajes del reconocimiento político que aparecerán en el postconflicto.

\section{Metodología: Condiciones para el despliegue de una experiencia etnográfica}

El proceso de formación política de la ORIVAC surge a partir del trabajo etnográfico que se desarrolló con la comunidad embera chamí asentada en el resguardo Wasiruma ${ }^{2}$ ubicado en el municipio de Vijes, departamento del Valle del Cauca. Con la comunidad profundizamos en las motivaciones morales que subyacen a los conflictos sociales y al papel que tenían las expectativas de autorrealización individual y colectiva en los procedimientos de deliberación política que se establecían con entidades del gobierno nacional (Castro Domingo \& Rodríguez Castillo, 2009); nos centramos fundamentalmente en el conflicto ético-político entre los habitantes del resguardo y el Instituto Colombiano de Bienestar Familiar.

Los líderes entrevistados consideran el resguardo como el logro de la lucha por el reconocimiento político de las comunidades indígenas en el Valle del Cauca. Los habitantes declaran que se trata de una expansión del derecho ancestral que ha sido posible gracias a la revitalización de la discusión social sobre el papel de los indígenas en la sociedad.

La comunidad embera chamí que conforma el resguardo, ha padecido el desplazamiento forzado causado por los proyectos hidroeléctricos realizados a comienzos de la década del noventa y la violencia entre grupos armados ilegales

\footnotetext{
2 Para tener más información del contexto ver el siguiente vídeo de Carlos Tobar (2014), Alcance Ético Político: https://www.youtube.com/watch?v=Jlhz01vRdX4
} 
Carlos Andrés Tobar Tovar, Formación política de la Organización Regional Indígena del Valle del Cauca para la participación en los escenarios del postconflicto en Colombia, perifèria 22(2), diciembre 2017

\section{revistes.uab.cat/periferia}

que se dio en el departamento durante 1995 y 2012 (Centro Nacional de Memoria Histórica, 2014). En la actualidad el resguardo está compuesto por 132 personas agrupadas en 32 familias asentadas en 82 hectáreas.

Debido a su cercanía con el municipio de Vijes y a las experiencias organizativas con grupos campesinos de la región y comunidades que habitan en la ciudad de Cali, se han introducido en el resguardo experiencias de reflexión política enmarcadas en la necesidad de consolidar un lenguaje político para el postconflicto.

A continuación, presentamos un mapa de los territorios de los grupos étnicamente diferenciados en el Valle del Cauca.

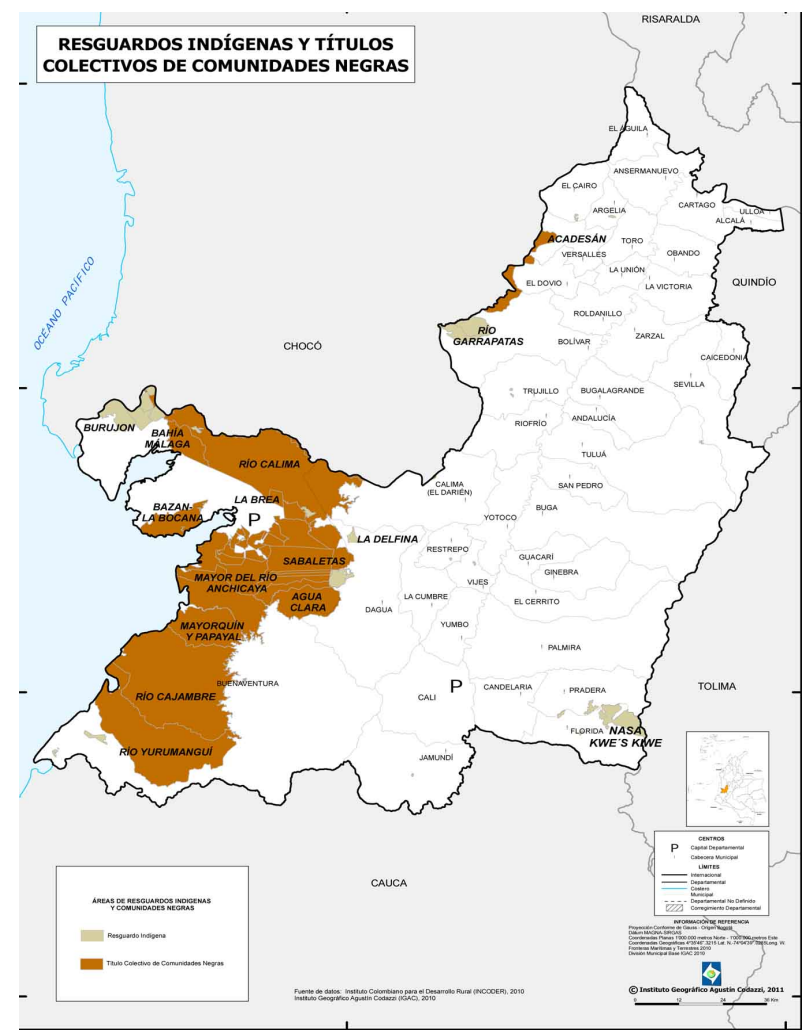

La perspectiva propuesta para el encuentro con los embera chami tuvo en cuenta las consideraciones precisadas en el Plan Nacional de Desarrollo 2014-2018, respecto a la necesidad de generar condiciones para que las comunidades participen en las prácticas deliberativas con el Estado en el territorio nacional. 
Carlos Andrés Tobar Tovar, Formación política de la Organización Regional Indígena del Valle del Cauca para la participación en los escenarios del postconflicto en Colombia, perifèria 22(2), diciembre 2017

\section{revistes.uab.cat/periferia}

En ese orden de ideas, la experiencia etnográfica se fundamentó en la comprensión de la dimensión normativa desde la cual los indígenas justifican sus expectativas de reconocimiento político (Castro Domingo, 2011); de esta forma, aspectos como la valoración social de lo indígena por parte de otros grupos de la región, así como la forma en que conciben la intervención del Estado en sus territorios, constituyen puntos de partida para el planteamiento de una interpretación antropológica de los conflictos por el reconocimiento (Krotz, 2002:125).

En los diferentes testimonios compilados en el transcurso del proceso se hacía evidente que la situación actual no favorece la construcción de un proyecto político de inclusión social, desde la perspectiva que tienen los indígenas del postconflicto (González González, 2016). En concordancia con ello, la descripción del agravio moral, y las formas de reconocimiento y desprecio referenciadas en el enmarcamiento social de la lucha por el reconocimiento de la comunidad Wasiruma, fueron importantes para perfeccionar una propuesta para pensar la vida de las comunidades en el espacio de la construcción de paz, considerando las expectativas y las posibilidades de la participación democrática de las comunidades indígenas en el departamento (Sánchez Botero, 2010).

De esta forma la experiencia etnográfica nos dio la pauta para el desarrollo de un proceso de formación, en el cual pudieran discutirse las expectativas que genera el cese del conflicto armado con las FARC-EP y lo que se espera del postconflicto y sus nuevos lenguajes jurídicos. 
Carlos Andrés Tobar Tovar, Formación política de la Organización Regional Indígena del Valle del Cauca para la participación en los escenarios del postconflicto en Colombia, perifèria 22(2), diciembre 2017

\section{revistes.uab.cat/periferia}

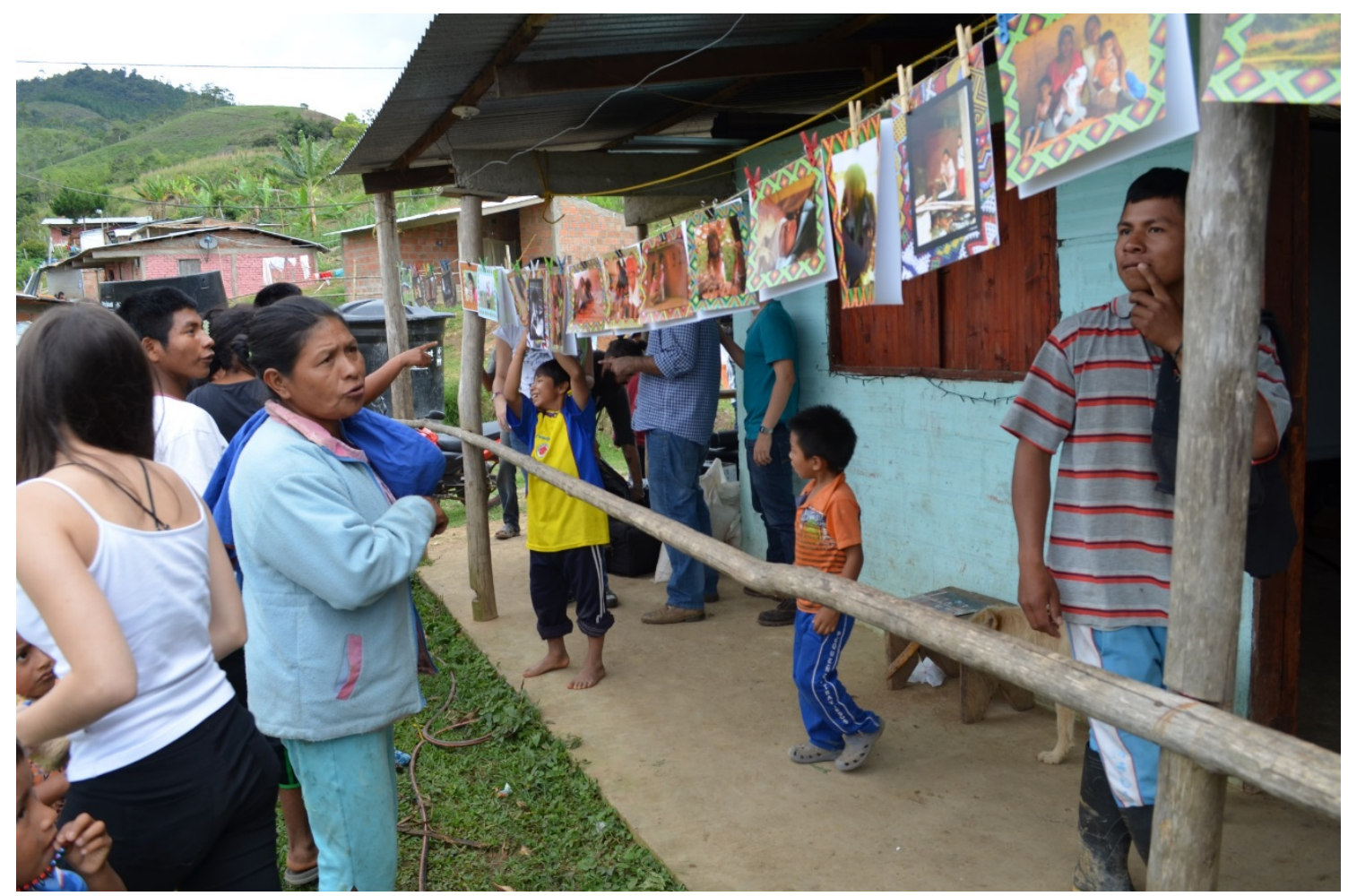

Fotografía tomada en diciembre de 2015 en el marco de la socialización de las actividades realizadas en el proyecto Gramática moral en el resguardo Wasiruma.

\section{Hacia un marco conceptual para pensar el postconflicto: desafíos}

En el siguiente apartado abordamos los ejes de la discusión conceptual e introducimos los testimonios de los participantes en las actividades previstas. Proponemos una forma de argumentación que equipara la reflexión teórica con las posturas de los líderes indígenas; dicho de otra manera, se sirve de lo expresado para dotar de contexto los abordajes teóricos. Al final, a modo de conclusiones, enfatizamos las ideas más relevantes en lo que atañe a la posibilidad de construir paz a través de los procesos sociales que desarrolla la ORIVAC.

Asumimos que la paz demanda una nueva comprensión del conflicto social y la construcción de alternativas para transformar los conflictos (Grueso D. I., 2009). Sin embargo, repensar las raíces del conflicto comprende un compromiso definitivo 
Carlos Andrés Tobar Tovar, Formación política de la Organización Regional Indígena del Valle del Cauca para la participación en los escenarios del postconflicto en Colombia, perifèria 22(2), diciembre 2017

\section{revistes.uab.cat/periferia}

con la justicia social, el reconocimiento y la restauración de la confianza en el Estado y el desarrollo económico (Castro Domingo, 2013). Esto representa un esfuerzo mayor al de las negociaciones en La Habana, e implica un proyecto a largo plazo que comienza con la cimentación de unas bases para la paz que se consoliden de manera intergeneracional (González González, 2016:521). Es por eso que la propuesta de formación política de la ORIVAC tenía como propósito aportar a la discusión cómo plantear espacios de educación sobre la construcción de paz y el postconflicto para comunidades indígenas. Al respecto presentamos el siguiente testimonio:

Existe una mesa de concertación nacional donde están los pueblos indígenas aquí en Colombia. Cada organización tiene su representación, eso tiene una negociación directamente con el ministerio y ahí se plantean los temas, se plantean las situaciones, las dificultades de cada territorio, de cada zona y se han tratado de llegar a algunos acuerdos. Pero de todas formas lo que quiere la, como en sí la política del pueblo indígena, es que la educación sea impartida como para educación indígena mas no como para una educación que en vez de mejorar la situación cultural lo empeore. Entonces ahí es donde de pronto el ministerio no ha cedido, inclusive se han levantado varias veces nuestros representantes allá, se han levantado porque ha habido acuerdos para esas posiciones. (Consejero en Educación, ORIVAC, entrevista realizada el 15 de marzo de 2014)

Adicional a la finalidad expuesta se reconoce una serie de obstáculos para la construcción de paz donde el problema de la diversidad, la desconfianza frente al Estado y la falta de garantías en el respeto a los derechos sobresalen por su carácter imperativo (Grueso \& Castellanos, 2010). Según el Plan Nacional de Desarrollo 2014-2018, la estrategia actual del Estado para afrontar estos desafíos se fundamenta en cuatro enfoques. El primer enfoque busca ofrecer las garantías para el disfrute efectivo de los derechos de los ciudadanos en el ejercicio pleno de su ciudadanía. El segundo enfoque busca la atención diferenciada que privilegia aquellos territorios donde el Estado está más ausente y donde las brechas sociales 
Carlos Andrés Tobar Tovar, Formación política de la Organización Regional Indígena del Valle del Cauca para la participación en los escenarios del postconflicto en Colombia, perifèria 22(2), diciembre 2017

\section{revistes.uab.cat/periferia}

entre la población rural y urbana está más marcada. El tercer enfoque es participativo y hace especial énfasis en la profundización de la democracia participativa, en la que los ciudadanos toman parte activa en la toma de decisiones que los afectan. Finalmente, un cuarto enfoque busca reconstruir la confianza entre la ciudadanía, y entre la ciudadanía y el Estado (Departamento Nacional de Planeación, 2016). En las finalidades formativas del proceso de la ORIVAC, estos enfoques convergen en la búsqueda de un diálogo propositivo que conecta las diferencias en aras del beneficio colectivo y el reconocimiento de los grupos sociales marginados, insistiendo en la generación de nuevos lenguajes para la protesta social y una reflexión crítica sobre la forma en que se realizan pactos con el Estado. Al respecto el siguiente testimonio:

A ver, nosotros pues en todos los años que hemos llevado acá, nosotros tenemos un problema con el gobierno colombiano que es que a nosotros nos dejan por allá, nos dejan muy, nos discriminan. O sea, las luchas que nosotros hemos ganado, la educación, los docentes que en estos momentos serán nombrados en propiedad, las hemos ganado con luchas, con propuesta, digámoslo así vulgarmente, boleando piedra a lado y lado. En esas protestas han caído líderes, pero entonces son legados que nos dejan a nosotros los jóvenes para que nosotros sigamos adelante y pues básicamente nosotros hemos ganado todo esto protestando.

¿Han existido otros mecanismos, otras maneras de poder hacer esos logros políticos? Claro, mire, nosotros como por ser digamos nos dicen minorías pero en realidad nosotros somos grandes, nosotros somos en personas somos muy extensas y pues la política ha llegado como a meternos por ese lado, como porque por unos votos, por tales, pero realmente en algunas comunidades llegan así "te voy a ofrecer tantas viviendas" y por ese lado se empiezan a meter (el Estado), cosa que nosotros anteriormente cometíamos ese error, nosotros sí. Pero realmente por el paso del tiempo y las experiencias sabemos que eso no se ha podido lograr ni se logrará, o sea, básicamente siempre hemos conseguido las cosas por las malas, hemos tratado de dialogar y 
Carlos Andrés Tobar Tovar, Formación política de la Organización Regional Indígena del Valle del Cauca para la participación en los escenarios del postconflicto en Colombia, perifèria 22(2), diciembre 2017

\section{revistes.uab.cat/periferia}

nunca, nunca nos han dado la respuesta. (Joven indígena, ORIVAC, entrevista realizada el 22 de febrero de 2013).

\section{Las justicias}

La justicia constituye un relato vinculante que se expresa en las demandas de los grupos socialmente excluidos (Fraser, 1996). En la historia de Colombia, nunca antes se había condicionado un proceso de paz al cumplimiento de unos mínimos en materia de justicia que favorezcan a las víctimas. Los intentos anteriores se acercaban a la lógica del armisticio en el cual los bandos cedían para favorecer la convivencia; tales fórmulas fracasaron porque los intereses económicos fragmentaban el poder de dichos pactos en las dinámicas de interacción entre el centro y las periferias (González González, 2016:450).

Ahora se han subscrito acuerdos internacionales cuya normatividad se integra a su bloque de constitucionalidad, y siempre está el recurso de los tribunales internacionales que pueden juzgar y castigar cuando un Estado no lo hace (Clavero, 2015). En esas condiciones la cuestión de fondo es cuánta justicia se debe exigir sin romper la esperanza de alcanzar una paz firme y duradera.

Y esa es precisamente la cuestión más comentada en el proceso de formación política de la ORIVAC, enfatizando el carácter polisémico del término 'justicia', desde su connotación puramente judicial hasta las variadas formas de la justicia social, que se desprenden de una cosmovisión y educación sobre la historia del indigenismo en Colombia.

Los indígenas de la ORIVAC reconocen una ganancia en la reflexión sobre la justicia que busca favorecer a las víctimas, pero advierten que esto puede inducir a una lectura intersubjetiva de la violencia, sin avanzar hacia un necesario empoderamiento de la sociedad. Es decir, que el favorecimiento de las víctimas puede conducir a una instrumentalización de tal estatus, asunto que trae consigo la pérdida de un discurso crítico sobre la vida social colombiana, en la cual se llevan a cabo prácticas sociales que invisibilizan las diferencias culturales. A continuación presentamos una de las intervenciones que dan cuenta del asunto descrito. 
Carlos Andrés Tobar Tovar, Formación política de la Organización Regional Indígena del Valle del Cauca para la participación en los escenarios del postconflicto en Colombia, perifèria 22(2), diciembre 2017

\section{revistes.uab.cat/periferia}

Yo creo que así como grandes logros después de la constitución del 91, ha sido el decreto con fuerza de ley, lo de la Ley de Víctimas, que es el decreto 4333, si tuviera la oportunidad de leerse ese decreto creo que en materia de derecho después de la constitución del 91, ese es el mayor logro que ha tenido el movimiento indígena, el mayor logro. $Y$ es que el Estado reconoce, el Estado no sé si metió la pata pero yo si estoy muy de acuerdo y es que yo estuve en esas conversaciones a nivel nacional, en la concertación. Y uno notaba de que la verdad los indígenas tienen una capacidad de diálogo y de negociación muy grande. El Estado a veces se queda corto de hacer un diálogo o de tener un debate con el movimiento indígena. El Estado le huye a un debate con indígenas. De eso me pude yo dar cuenta ya de manera muy puntual cuando me senté con los ministros a concertar este decreto, decreto ley, porque este decreto ley quedó escrito como nosotros queríamos y con las palabras que nosotros queríamos, el Estado allí sí en cierta forma se puede decir que nos dio un reconocimiento muy grande, en materia de derechos. Porque este decreto logró muchas cosas, por ejemplo, que el Estado entendiera de que el territorio tiene que ser reparado porque se le ha hecho mucho daño. Ahora, imagínese ¿cómo se puede reparar el territorio? Pues el Estado no tiene ni idea cómo hacer una reparación, los indígenas de pronto tenemos idea de cómo hacer un proceso de reparación a la tierra que tanto se le ha maltratado. Porque nosotros creemos que ella es igual de, tiene las mismas, igual de vida que nosotros, tan así que vivimos de ella. (Consejero Mayor, ORIVAC, entrevista realizada el 26 de abril de 2014).

Los indígenas plantean que no se puede depositar toda la esperanza en la firma del acuerdo de La Habana, como si ello fuera, por sí mismo, a transformar las dimensiones más estructurales de la injusticia social. $Y$ aunque reconocen las bondades de la justicia transicional, creen que a hay que apreciarla en su verdadero alcance. Se espera que tal forma de justicia haga énfasis en la reparación económica, el perdón y la reconciliación como ejes reconfiguradores del tejido social.

\section{Justicia transicional}


Carlos Andrés Tobar Tovar, Formación política de la Organización Regional Indígena del Valle del Cauca para la participación en los escenarios del postconflicto en Colombia, perifèria 22(2), diciembre 2017

\section{revistes.uab.cat/periferia}

Se ha documentado que la mayoría de los delitos cometidos en Colombia se dan por fuera del conflicto armado (Villa Holguín \& Insuasty Rodriguez, 2014). El reciente pasado de la violencia paramilitar en el Valle del Cauca nos pone ante un escenario de difícil solución, si consideramos los recursos limitados la justicia ordinaria y las supuestas posibilidades extraordinarios de la justicia transicional (Centro Nacional de Memoria Histórica, 2014).

Archilla (2015) manifiesta que la violencia contra los indígenas se incrementa con la aparición de grupos paramilitares quienes tuvieron incidencia en los desplazamientos forzados de comienzos de siglo. Así, por ejemplo, el Tribunal Indígena convocado por la Organización Nacional Indígena de Colombia (ONIC) en 2008 en Atanquez (César) expidió una declaración en la que se dice: "Durante el gobierno del Presidente Uribe han sido asesinados 1119 de nuestros hermanos, siendo el año más cruento el de 2002 donde (sic) fueron masacrados 426 indígenas. Y se agrega una cuantificación de los victimarios: del total de estos asesinatos el Estado colombiano es responsable del 61,7\%, los grupos paramilitares $18,12 \%$, los grupos guerrilleros del $13,7 \%$ y el $6,48 \%$ restante por otros actores entre empresarios, colonos y demás" (Archilla, 2015:26).

La masacre del Nilo en diciembre de 1991 anunciaba la llegada del paramilitarismo encarnado en la organización Autodefensas Unidas de Colombia (AUC). La Ilegada de este grupo coincidió con la imposición de un modelo de apertura neoliberal que privilegiaba la minería extractivista en territorios de origen de comunidades indígenas. Las actividades de las AUC implicaron despojo de tierras, violaciones a los derechos humanos, desposesión de derechos y aumentaron el peligro para comunidades rurales ubicadas en los departamentos de Antioquia, Valle del Cauca y Cauca. En palabras de los participantes a las reuniones:

(...) nosotros andábamos era como campesinos, éramos campesinos, indígenas campesinos, porque de donde nosotros vivíamos la CVC [Corporación Autónoma Regional del Valle del Cauca] nos sacó, mataron unos cuantos líderes porque es que los que estaban allí los líderes ellos opusieron a salirse de ese territorio porque ese era un territorio ancestral, era un territorio 
Carlos Andrés Tobar Tovar, Formación política de la Organización Regional Indígena del Valle del Cauca para la participación en los escenarios del postconflicto en Colombia, perifèria 22(2), diciembre 2017

\section{revistes.uab.cat/periferia}

donde nosotros nacimos y criamos. $Y$ entonces ellos se opusieron a eso y entonces esa gente mataron a los líderes y entonces nosotros ya nos iban a matar a todos nosotros y lo que nosotros hicimos fue pues al matar a los demás, los otros mayores que quedaron pues lo que hicimos fue salirnos como se dice pues volados a la media noche a cuatro, cinco horas de camino y ya luego lo que pusimos fue a andar así cada uno por su lado, a criarse sus hijos como pudieron. (Mujer participante de la ORIVAC, entrevista realizada el 15 de septiembre de 2015).

Ante un panorama tan complejo como este, ¿cuenta Colombia con un aparato judicial capaz de hacer justicia? Creemos que ni Colombia, ni ningún país que sale de una guerra, pueden hacerlo. Ese es el sentido de la justicia transicional, en la que prima la búsqueda del bien supremo de la paz a través de una aplicación proporcional de la pena, con tal de que alcance algo de reconocimiento de la culpa, de petición de perdón y de garantía de no repetición. ¿Por qué tendría que ser el castigo más importante si hay reparación moral y material de las víctimas y la reconstrucción del tejido social? Son muchos los que piensan que un rigorismo jurídico no puede socavar los derechos y los deberes de la política, perspectiva que los miembros de la ORIVAC comparten.

\section{Las víctimas}

Ahora bien, en un proceso así siempre existe la posibilidad de instrumentalizar políticamente a las víctimas, como que las víctimas sean eternizadas en su rol y no den paso a una adecuada normalización de la vida social (Honneth, 2006). Aprendimos con los Wasiruma que existe un juego de expectativas políticas frente a la negoción de un acuerdo de paz y que esto implica a veces 're-victimizar a las víctimas'. Dicho de otro modo: generar una gratificación económica o cultural que favorece el hecho de ser víctima sin que eso signifique un reacomodo de su rol social. Al respecto referenciamos el siguiente relato:

(...) siempre nos han definido como vulnerables y todo el tema, pero nunca se han sentado realmente a ver por qué somos vulnerables. O sea, no son vulnerables no mas porque son indígenas, porque seamos indígenas, es por el 
Carlos Andrés Tobar Tovar, Formación política de la Organización Regional Indígena del Valle del Cauca para la participación en los escenarios del postconflicto en Colombia, perifèria 22(2), diciembre 2017

\section{revistes.uab.cat/periferia}

sentir de los indígenas de esa vulnerabilidad, por decir, nosotros no somos vulnerables porque si, nosotros somos vulnerables porque no tenemos de comer por ejemplo, no tenemos tierras, eso es un estado de vulnerabilidad, la gente no lo ve así, pero si no tenemos territorio no tenemos nada, si no tenemos territorio no tenemos nada, empezando porque milenariamente y la cosmovisión dice que los pueblos indígenas siempre hemos sido pescadores, hemos andado de arriba para abajo viviendo de lo que la tierra nos da, pero si aquí no tenemos esas circunstancias, por eso somos vulnerables. Porque nos toca aprender cosas que no están dentro de nuestro modo de vivir, ese es el tema de la vulnerabilidad, pero eso nunca lo han visto así, "ah son vulnerables porque son indígenas" y de pronto hablan y se visten diferentes. Pero el tema de la vulnerabilidad nosotros lo vemos por ese lado, que nos han quitado, es como si decir, a ti te van a quitar. ¿A ti quien te da de comer? Ese es el tema de la vulnerabilidad (Joven participante, ORIVAC, entrevista realizada el 1 de marzo de 2014).

Hay varios tipos de víctimas en Colombia. Unos los que han sido vulnerados por los actores del conflicto en su integridad física y emocional, en sus bienes, en su honra, en su estilo de vida, en su espacio vital y en la destrucción de sus lazos afectivos. Otros los que han sido arrastrados al conflicto por efecto de violencias, de exclusiones, de persecuciones, de injusticias momentáneas o crónicas. Así, unos se relacionan con el conflicto como víctimas, o como vengadores de las víctimas, o tratando de ser victimizados tras el triunfo de alguna de las partes en conflicto. $Y$, lo más complejo: víctima y victimario se entremezclan fuertemente, por la superposición de varios conflictos (Honneth, 2011).

En cuanto se rescata el rol estructurante de la política en el conflicto (Mouffe, 2003), la política rescata para sí su dimensión reconstructiva de la vida en común, el Estado recupera su derecho a tomar decisiones en materia de perdón y de agente de la reconciliación, y esto se potencia aún más cuando el propio Estado asume acciones de petición de perdón y de reparación de las víctimas.

\section{Otras injusticias}


Carlos Andrés Tobar Tovar, Formación política de la Organización Regional Indígena del Valle del Cauca para la participación en los escenarios del postconflicto en Colombia, perifèria 22(2), diciembre 2017

\section{revistes.uab.cat/periferia}

Dándole su peso específico a la connotación más punitiva de la justicia, de la cual la justicia transicional es todavía una variación, se abre el cuestionamiento de las causas objetivas del conflicto en clave de justicia social (Uribe, 1999). En el plano anterior todavía se navegaba en lo intersubjetivo y se formula la pregunta por la relación entre el delito, el delincuente y el castigo o entre la víctima, el perdón y la reparación.

Las dimensiones más estructurales de la injusticia, aquellas ancladas en los universos simbólicos que subordinan a amplios sectores de la población y que han jugado un papel más determinante en la génesis del conflicto armado (Honneth, 2009), van más allá de lo que se pudo dialogar en los acuerdos de la Habana, los miembros de la ORIVAC manifiestan que el conflicto armado no es la única fuente de injusticias y que son las relaciones de poder con las instituciones del Estado las que deben ser revisadas.

Por el contrario, la percepción de injusticia, en términos de la estructura básica de la sociedad puede concebirse como una expresión de inestabilidad política (Rawls, 1993). En otras palabras, si los miembros de una sociedad, no entienden o no aceptan los criterios que asignan cargas y beneficios, y validan los regímenes de propiedad, inclusión y exclusión social, la sociedad entra en una crisis de legitimidad que se expresa en un conflicto social (Krotz, 2002).

La tradición que ha pensado la justicia social en términos de las inequidades, ha privilegiado una gramática más cercana a la economía política y al derecho. La vinculación del reconocimiento a la justicia implica, por decirlo así, un cambio de registro; aquel relacionado con el carácter social de una experiencia psicológica; con cómo los otros inciden notoriamente en la estructuración de la identidad personal y colectiva; más concretamente, con los efectos que cada ser humano deriva del hecho de ser o no reconocido (Honneth, 1997). Esta vía de interpretación resulta conveniente para el proceso de formación política de la ORIVAC porque le da un lugar preponderante a los sentimientos de dignidad vulnerada que se encuentran en la base de su lucha por el reconocimiento. Al respecto el siguiente relato: 
Carlos Andrés Tobar Tovar, Formación política de la Organización Regional Indígena del Valle del Cauca para la participación en los escenarios del postconflicto en Colombia, perifèria 22(2), diciembre 2017

\section{revistes.uab.cat/periferia}

(...) para nosotros no existía educación, nuestra educación era la propia, la de nosotros, esta otra educación pues todavía no era importante para nosotros porque no sabíamos ni pa' qué servía. Porque en la cultura de nosotros la ley de nosotros es la palabra y nosotros creíamos en la palabra y era inviolable, pero acá nos dicen que lo que no está escrito no sirve, lo que no está escrito no es nada, que la palabra se lo lleva el viento han dicho por acá afuera, mientras que para nosotros eso es sagrado. Por eso al indígena cuando no le, cuando lo que está escrito tampoco lo violan y no lo cumplen, es peor, por eso es que los indígenas se movilizan mucho, por eso es que los indígenas se toman las vías, porque el Estado así esté escrito incumple, el Estado no es serio. (Consejero de salud, ORIVAC, entrevista realizada el 17 de marzo de 2015).

\section{Algunos ejemplos de injusticias distributivas y de reconocimiento}

El déficit a este respecto se evidencia ante todo en la abismal inequidad, inusual si se compara con el resto del continente latinoamericano (Aragón Andrade, 2014). Y quizás no hay ejemplo tan manifiesto como el problema de la tierra, que llegó casi que intacto desde la época colonial y que históricamente ha sido detonante de conflictos armados desde el siglo XIX (Balcázar, López, \& Orozco, 2001). La violencia de los años cuarenta y cincuenta fue, en gran parte, una contrarreforma agraria y lo mismo han sido los desplazamientos forzados propiciados por los llamados 'pájaros' y más recientemente por narcotraficantes y paramilitares e incluso por las actuales bandas criminales (Centro Nacional de Memoria Histórica, 2014).

Unas veces para sembrar caña de azúcar, otras palma africana, para ampliar la ganadería extensiva y ahora para llevar la agroindustria a los antiguos territorios nacionales (Centro Nacional de Memoria Histórica, 2014). Han sido vanos intentos justicieros como la Ley 200 de 1936, la Ley de Reforma Agraria del año 1962 y la creación del Instituto Colombiano de la Reforma Agraria (INCORA) (Balcázar, López, \& Orozco, 2001). Los programas de la entidad ofrecían el capital para la adecuación de los terrenos pero no títulos de propiedad, asunto que desencadenó 
Carlos Andrés Tobar Tovar, Formación política de la Organización Regional Indígena del Valle del Cauca para la participación en los escenarios del postconflicto en Colombia, perifèria 22(2), diciembre 2017

\section{revistes.uab.cat/periferia}

protestas que muchas veces fueron reprimidas de forma violenta por el Estado como por los afanes propagandísticos de las organizaciones de izquierda. Un ejemplo asociado con esta descripción lo encontramos en la toma de las instalaciones del INCORA en la ciudad de Cali en el año 1991, por cuenta de las comunidades indígenas de aquel entonces. A continuación el testimonio de uno de los participantes del suceso.

El tema de la territorialidad y el tema de la reclamación de los derechos inician desde 1989. Los indígenas llegan a hacer ese proceso y con experiencia o sin experiencia digamos ellos llegan y piden que el departamento reconozca que existen los pueblos indígenas del Valle del Cauca. A través de la Oficina de Asuntos Indígenas que existía en ese momento pues se apoyaba y todo eso pero hasta ahí no más. (...) En el 1991 los indígenas preparan la primera toma. Hacen una toma y tomaron al INCORA, ahí vinieron diferentes pueblos y eso pues coordinaron todo, era un teatro yo no me acuerdo donde sería que nos metieron a todos los indígenas del Valle allí. Entonces como nunca la gente ha llegado a ver, o sea vinieron gente del Pacífico digamos así semidesnudos, toda esa parte, entonces la gente esa fue la distracción de la gente. Entonces llegaron y se quedaron en las oficinas. (Miembro fundador, ORIVAC, entrevista realizada el 18 de enero de 2012).

Prada (2004) destaca la puesta en marcha de movilizaciones para la ocupación ilegal de tierras, así como también medidas represivas ejercidas por terratenientes que encontraron amparo en el Estado. Del 2005 hasta la actualidad ha primado el espíritu de la repartición de la tierra a quienes ya la tienen en abundancia. Ante la actual política de restitución de tierras, ya se concibe en el horizonte el rearme de los grupos paramilitares para impedir el retorno de los desplazados. En este marco de posibilidades los miembros de la ORIVAC plantean: ¿Se puede creer que, sin democratizar la tenencia de la tierra, se tendrá paz duradera en el postconflicto?

Otra fuente de injusticia la constituye la forma particular en que se da en Colombia la tensión centro-periferia, que en casi todos los países no es más que la oposición 
Carlos Andrés Tobar Tovar, Formación política de la Organización Regional Indígena del Valle del Cauca para la participación en los escenarios del postconflicto en Colombia, perifèria 22(2), diciembre 2017

\section{revistes.uab.cat/periferia}

de intereses entre la ciudad capital y la provincia (Uribe, 1999). Las comunidades indígenas han vivido una sumatoria de injusticias ligadas al conflicto, mientras el país mestizo, anclado en sus prejuicios raciales, prefería pensar la modernización del país de cara a Estados Unidos y Europa. Al respecto Gros (1993) ofrece dos ejemplos de cómo los modos de concebir a los indígenas incidieron en los imaginarios sociopolíticos anteriores a la Constitución Política de 1991. El primer ejemplo alude a la postura de Laureano Gómez, quien fue presidente de Colombia de 1948 a 1953. Para Gómez los indígenas constituían la imagen del atraso y subdesarrollo que nos alejaban de la visión idealizada de los países europeos y de Estados Unidos. El segundo ejemplo lo encontramos en las masacres efectuadas en contra de los indígenas Cuiva en 1967, y la total ausencia de justicia en tanto que se consideró que las personas asesinadas no eran ciudadanos regulares y que, debido a sus rasgos raciales, el delito carecía de pena (Gros, 1993).

Estos ejemplos nos advierten sobre discursos que invisibilizan la periferia y promueve las imágenes idealizadas que le interesan al centro. Sin esa representación espacial y actitudinal de la nación andina, Colombia no hubiera estado de espaldas, durante décadas enteras, a un conflicto cruel. En esa indiferencia se expresan actitudes racistas, regionalistas y culturales que aún ocurren (Gros, 1997).

\section{Educación para la paz}

En el marco de los problemas esbozados, la primera tarea de un programa de formación para indígenas consistió en el cultivo de las virtudes cívicas, considerando la experiencia organizativa de la ORIVAC y las cosmovisiones de las comunidades que también exaltan la necesidad de ponderar la solidaridad, la autonomía y el respeto como valores relevantes para la vida social. Como lo hemos venido advirtiendo: de lo que se trata es de crear las condiciones éticas y políticas para tramitar de otra manera los conflictos, a fin de que ellos no se escalen de manera incontrolada. A continuación un testimonio de uno de los participantes en la reunión. 
Carlos Andrés Tobar Tovar, Formación política de la Organización Regional Indígena del Valle del Cauca para la participación en los escenarios del postconflicto en Colombia, perifèria 22(2), diciembre 2017

\section{revistes.uab.cat/periferia}

Porque entiendo que hoy por ejemplo están haciendo unas casas y que eso supone una forma de minga, pero también entiendo que a veces se cita a protesta, una situación que se llama los trabajos comunitarios ¿cierto? Entonces inclusive dentro de nuestro proyecto pedagógico existe unas áreas comunitarias donde el niño tiene que, tiene no, debe, intercambiar o debe acompañar en los trabajos comunitarios a los mayores. Por ejemplo, aquí se siembra mucho la caña, el maíz, entonces el niño yo llevo los niños en una, en un día programado por la comunidad y que eso está dentro del plan de estudio, que el niño, los niños deben participar a lo menos mirar y aporta o siembra su granito de maíz en la tierra para que él vaya como conociendo cómo se trabaja la tierra y cómo es que tal cultivo se va a sembrar. Entonces eso hace parte de un proyecto de la minga. Aquí, por ejemplo, hay mingas ya que se programan a cualquier momento, por ejemplo hoy es sábado y uno dentro de su normatividad dice no, el docente sábado y domingo es día de sus vacaciones pero no acá, uno vive con la comunidad y en cualquier momento se trabaja, así sea en día de descanso. Pero uno pues porque uno vive comprometido con el proceso y uno no le ve si es festivo o no es festivo sino que se trabaja en mingas comunitarias. (Consejero en Educación, ORIVAC, entrevista realizada el 15 de marzo de 2015).

Para esto es necesario tener claro que la paz no se aclimata con rigoristas morales, propensos al dogmatismo y la intolerancia, ni con individuos autosatisfechos. Urgen individuos concernidos con la vida en común y esto se logra a través de una ética cívica (Arendt, 1998); que no es el 'civismo' que incorporaba nuestro currículo escolar hace muchas décadas y que se agotaba en una información sobre la estructura del Estado y un aprendizaje dogmático de las conductas socialmente aceptables (Grueso \& Castellanos, 2010). Se trata de una 'ética para la ciudadanía', de la cual tienen necesidad creciente todas las sociedades que tienen problemas ligados a la convivencia en la diversidad, y la colombiana que ha emprendido la búsqueda de un nuevo lenguaje para nombrar y pensar la paz (González González, 2016). 
Carlos Andrés Tobar Tovar, Formación política de la Organización Regional Indígena del Valle del Cauca para la participación en los escenarios del postconflicto en Colombia, perifèria 22(2), diciembre 2017

\section{revistes.uab.cat/periferia}

La formación ética para la ciudadanía es una formación para la libertad y la igualdad. Libertad e igualdad en la relación con el Estado y en las relaciones horizontales con los otros. Eso en Colombia ha sido débil y se ha erosionado por acción del conflicto, por lo que hay que revertir lo que las lógicas bélicas han degradado (Prada, 2004).

Aquí es donde resulta importante hablar de educación, en el afianzamiento de "la amistad cívica"; una que se base en una ética de mínimos y no se encarnice con el diferente. El problema es que la escuela hegemónica está mal preparada para acometer con éxito esa misión (Pueblo Embera Chamí, 2012). Para los miembros de la ORIVAC, algunas de las políticas de los recientes gobiernos con respecto a la educación, difícilmente podrían considerarse experiencias de democratización; al respecto se plantea que la democratización propuesta requerirá básicamente de nuevos marcos orientadores, para pensar lo que significa construir paz en nuestros tiempos.

\section{A modo de conclusión}

De la mano de los líderes indígenas de la ORIVAC aprendimos que la construcción de la paz va más a allá de las posibilidades de la firma del acuerdo de la Habana para superar el conflicto armado, pues involucra variadas formas de violencia circunscritas en un entramado social de difícil interpretación (Grueso \& Castellanos, 2010). Se trata así de repensar el papel y alcances de la política desde la perspectiva de las comunidades indígenas, que se encuentran desarrollando procesos de participación ciudadana y de recuperación del espacio simbólico de lo político (Gledhill, 2000).

Desde la perspectiva de los líderes de la ORIVAC se plantea el postconflicto como una experiencia de reconocimiento cultural donde se redimensiona el papel de los indígenas en la sociedad. Las demandas de visibilidad, inclusión y participación democrática están muy presentes en el modo en que los líderes argumentan sobre los modos en que se puede construir la paz. 
Carlos Andrés Tobar Tovar, Formación política de la Organización Regional Indígena del Valle del Cauca para la participación en los escenarios del postconflicto en Colombia, perifèria 22(2), diciembre 2017

\section{revistes.uab.cat/periferia}

Desde esta perspectiva, la participación indígena exige una visión de la política en la que se redimensiona la participación como criterio esencial y no siempre permitido para los grupos étnicamente diferenciados en Colombia. La necesidad de afianzar un debate público y un cuestionamiento a las variadas formas de racionalidad propias del poder hegemónico en el Valle del Cauca, posibilita la apertura de espacios de reflexión sobre el postconflicto.

Destacamos el intento pluralista de pensar la racionalidad propia del conflicto social colombiano desde una perspectiva indígena. El interés por una construcción de paz asociada a la necesidad e importancia del conflicto, puede cobrar una connotación amplia: pensar en paz implica reconocer, valorar y alentar, paralelamente, la condición de pluralidad y divergencia del mundo de lo humano.

Una manera de reflexionar la experiencia señala que la construcción de paz implicará en últimas, tomar consciencia plena del pluralismo y de los conflictos en espacios de aparición, donde confluyen significados, emociones y sentidos varios de justicia. Justicia asociada a la forma como individuos, grupos y comunidades ven expresada la idea de una sociedad realmente incluyente y equitativa (Krotz, 2002). El proceso de la ORIVAC nos permite empezar a estudiar los cambios del lenguaje político dentro de las connotaciones del postconflicto en la región.

\section{Bibliografía}

Aragón Andrade, O. (2014). La construcción de la diversidad jurídica desde el Estado. El proceso de oficialización de la justicia indígena en Michoacán. Relaciones, 115-147.

Archilla, M. (2015). Violencia y memoria indígena en Cauca y la Guajira. Memoria y Sociedad, 24-40. http://dx.doi.org/10.11144/Javeriana.mys19-38.vmic

Arendt, H. (1998). La condición humana. Barcelona: Paidós.

Balcázar, A., López, N., \& Orozco, M. (2001). Colombia: Alcances y lecciones de su experiencia en reforma agraria. Santiago de Chile: Cepal.

Castro Domingo, P. (2011). Cultura política:una propuesta socio-antropológica de la construcción de sentido en la política. Región y sociedad, vol. xxiii (50). 
Carlos Andrés Tobar Tovar, Formación política de la Organización Regional Indígena del Valle del Cauca para la participación en los escenarios del postconflicto en Colombia, perifèria 22(2), diciembre 2017

\section{revistes.uab.cat/periferia}

(septiembre-diciembre de 2013). Mercado de suelo y resistencia política . Cuicuilco(58), 60-76.

Castro Domingo, P., \& Rodríguez Castillo, L. (2009). Antropología de los procesos políticos y del poder. Ateridades, 107-127.

Centro Nacional de Memoria Histórica (2014). "Patrones y campesinos": tierra, poder y violencia en el Valle del Cauca (1960-2012). Bogotá: CNMH.

Clavero, B. (2015). Consulta indígena e historia colonial: Colombia y las Américas, de México a Bolivia, entre derechos humanos y derecho constitucional, 1989-2014. Quaderni fiorentini per la storia del pensiero giuridico moderno, $589-661$.

Departamento Nacional de Planeación (2016). Plan Nacional de Desarrollo 20142018. [En línea] https://www.dnp.gov.co/Plan-Nacional-deDesarrollo/Paginas/Que-es-el-Plan-Nacional-de-Desarrollo.aspx (Última consulta: 17 de noviembre de 2017)

Fraser, N. (1996). Redistribución y reconocimiento: Hacia una visión integrada de justicia de género. Revista internacional de Filosofía Política, 35-52.

Gledhill, J. (2000). El poder y sus disfraces: perspectivas antropológicas de la política. Barcelona: Bellaterra.

González González, F. E. (2016). Poder y violencia en Colombia. Bogotá: Gente Nueva.

Gros, C. (1993). Derechos indígenas y nueva Constitución en Colombia. (I. d. Colombia, Ed.) Análisis Político(19), 8-24.

Gros, C. (1997). Indigenismo y etnicidad: el desafío neoliberal. En M. V. Uribe, \& E. Restrepo, Antropología en la modernidad: identidades, etnicidades y movimientos sociales en Colombia (pp. 15-59). Bogotá: Instituto colombiano de Antropología.

Grueso, D. I. (2009). Identidades étnicas, justicia y política transformativa. En G. Castellanos, D. I. Grueso, \& M. Rodríguez, Identidad, cultura y política: perspectivas conceptuales, miradas empíricas (pp. 283-307). Cali: Universidad del Valle.

Grueso, D., \& Castellanos , G. (2010). Identidades colectivas y reconocimiento. Razas, etnias, géneros y sexualidades. Cali: Programa editorial Universidad del Valle.

Honneth, A. (1997). La lucha por el reconocimiento. Por una grmática de los conflictos morales. Barcelona: Grijalbo. 
Carlos Andrés Tobar Tovar, Formación política de la Organización Regional Indígena del Valle del Cauca para la participación en los escenarios del postconflicto en Colombia, perifèria 22(2), diciembre 2017

\section{revistes.uab.cat/periferia}

Honneth, A. (2006). Redistribución como reconocimiento: respuesta a Nancy Fraser. En N. Fraser, \& A. Honneth, ¿Redistribución o reconocimiento? (pp. 89-148). Madrid: Ediciones Morata.

Honneth, A. (2009). Crítica del agravio moral. Patologías de la sociedad contemporánea. Buenos Aires: Fondo de Cultura Económica de Argentina, S.A.

Honneth, A. (2011). La sociedad del desprecio. Madrid: Editorial Trotta.

Instituto Colombiano de Bienestar Familiar (29 de Abril de 2011). Resolución 4025 de 2011. [En línea]:

http://www.icbf.gov.co/cargues/avance/docs/resolucion_icbf_4025_2011.ht $\mathrm{m}$

Instituto Colombiano para el Desarrollo Rural (2015). Instituto Georgrafico Agustín Codazzi, Mapa de Resguardos Indígenas y Títulos Colectivos de Comunidades Negras. [En línea]:

http://sigotn.igac.gov.co/sigotn/PDF/Resguardos_Negras_Nal_Soc_V2.pdf

Krotz, E. (2002). Antropología jurídica: perspectivas socioculturales en el estudio del derecho. Barcelona: Editorial Anthropos.

(2002). La otredad cultural entre utopía y ciencia - un estudio sobre el origen, el desarrollo y la reorientación de la antropología. México: Fondo de Cultura Económica.

Mouffe, C. (2003). La paradoja democrática. Madrid: Editorial Gedisa.

Prada, E. (2004). Luchas campesinas e indígenas. En M. Archilla, Á. Delgado, M. García, \& E. Prada, 25 años de Luchas Sociales en Colombia 1975-2000 (págs. 11-28). Bogotá: Ediciones Antropos Ltda.

Pueblo Embera Chami. (2012). Plan de salvaguardia del pueblo Ebera Chami del Valle del Cauca. Cali: Organización Regional Indígena Valle del Cauca (ORIVAC).

Rawls, J. (1993). Liberalismo Político. México DF : Fondo de cultura económica.

Sánchez Botero, E. (2010). Los pueblos indígenas en Colombia. Bogotá: UNICEF.

Uribe, M. (1999). Comunidades, ciudadanos y derechos. En F. Cortés Rodas, \& A. Monsalve Solórzano, Multiculturalismo. Los derechos de las minorías culturales (págs. 17-37). Medellín, Antioquía, Colombia: Instituto de Filosofía de la Universidad de Antioquía. 
Carlos Andrés Tobar Tovar, Formación política de la Organización Regional Indígena del Valle del Cauca para la participación en los escenarios del postconflicto en Colombia, perifèria 22(2), diciembre 2017

\section{revistes.uab.cat/periferia}

Villa Holguín, E., \& Insuasty Rodriguez, A. (2014). Conflictos sociales y coyunturas de paz en Colombia. Decadencia occidental y potencialidades del latinoamericanismo. Ágora U.S.B, 419-435. 